\title{
Os lugares de memória da ditadura: disputas entre o poder público e os movimentos sociais
}

\author{
Joana DArc Fernandes Ferraz ${ }^{1}$ \\ Lucas Pacheco Campos ${ }^{2}$
}

\begin{abstract}
Resumo
Os lugares de memória, na perspectiva de Pierre Nora (1990), são espaços de eternização de uma memória de um grupo que já não consegue mais ser evocada espontaneamente pela memória coletiva. Há uma grande disputa entre o Estado e os movimentos sociais em relação à preservação do patrimônio histórico que faz alusão ao golpe militarempresarial brasileiro (1964-1985), no Rio de Janeiro. Pretendemos pensar o lugar político destes lugares memórias, a partir das querelas em torno da patrimonização de alguns espaços e prédios, que fazem apologia ao golpe e à ditadura, na cidade do Rio de Janeiro. A política que tem sido efetuada até agora pelo Estado pode ser definida como conciliatória. Não obstante, os movimentos sociais reclamam a inserção de suas vozes nestes lugares, considerando-as, silenciadas ou esquecidas. Interessa-nos analisar estas disputas e as seus reflexos na sociedade.
\end{abstract}

Palavras-chave: ditadura militar-empresarial brasileira; memória; disputas; patrimônio.

\section{Abstratct}

The sites of memory, in Pierre Nora's perspective (1993), are spaces of eternalization of a memory's group that can no longer be spontaneously evoked by collective memory. There is a large dispute between the State and the social movements regarding the preservation of historical heritage that alludes to the Brazilian military-business coup (1964-1985)

\footnotetext{
${ }^{1}$ Professora do Curso de Sociologia, da Universidade Federal Fluminense (UFF). joanadferraz@gmail.com

${ }^{2}$ Doutorando em Políticas Públicas e Formação Humana pela Universidade do Estado do Rio de Janeiro (UERJ)

lucas-pcampos@hotmail.com
} 
in Rio de Janeiro. We intend to think the political place of these sites of memories, consulting the patrimony of spaces and buildings which advocate for the coup and dictatorship, in the city of Rio de Janeiro. The policy that has been practiced so far by the State can be defined as conciliatory. However, the social movements demand the insertion of their voices in these places, considering them, silenced or forgotten. We are interested in analyzing these disputes and how they reflect on society.

Key words: Brazilian military-business dictatorship; memory; patrimony.

Contar essas memórias significa, sem dúvida, tentar navegar por outras histórias, diferentes da oficial que nos tem sido apresentada e afirmada como única $e$ verdadeira. Há relatos que atravessam e constituem todos nós, mesmo os que não tiveram com aqueles tempos implicações tão tensas ou que neles não viveram. (Cecília Coimbra, 2011, p. 40 Uma das fundadoras do GTNM-RJ)

É desta história que vamos falar um pouco, de uma história onde as classes populares não são meras expectadoras dos fatos, mas produtoras dos acontecimentos. De uma história onde a subjetividade dominante - apesar de seu poderio e tentativas - não consegue silenciar e ocultar a produção de espaços singulares, de práticas diferentes e eliminar a memória histórica de uma outra memória. (DOSSIÊ DE MORTOS E DESAPARECIDOS, 1995, p. 23)

\section{Introdução}

No conjunto de reflexões, depois dos cinquenta anos do golpe militar-empresarial brasileiro ${ }^{3}$, no que se refere ao sentido de preservação do passado, um dos maiores problemas é o das

\footnotetext{
${ }^{3}$ Ver mais em 1964 - A Conquista do Estado: ação política, poder e golpe de classe, de René Dreifuss (1987), A natureza de Classe do Estado brasileiro, de João Quartim de Moraes (2014) e A Ditadura do Grande Capital, de Octavio lanni (1981)
} 
disputas pelas memórias coletivas. Uma dessas querelas refere-se à própria denominação deste evento. As denominações "golpe militar-empresarial brasileiro" e "ditadura militar-empresarial brasileira" têm, neste artigo, um propósito político. Intenta afirmar que a participação da sociedade civil, tanto no evento do golpe, como durante todo o período ditatorial "era preponderantemente empresarial, havendo diversos agentes da burguesia brasileira que fizeram parte do pacto político estabelecido no pós-1964" (CAMPOS, 2014, p. 35). Essa escolha política tem como objetivo ressaltar a importância das ligações associativas entre a classe burguesa, o golpe de 1964 e as ações do Estado ditatorial brasileiro.

Considerando que é impossível a reconstrução diária da memória e igualmente impossível a sua destruição completa, alguns aspectos nos parecem relevantes e necessários para uma possível política de luto e de resistência. Pensar o lugar político da memória deste período em nossa sociedade, sem ignorar o passado ou essencializá-lo talvez possa nos auxiliar. As cicatrizes produzidas pelo esquecimento e pelo silêncio podem nos levar à reatualização dos traumas individuais e coletivos.

Dessa forma, com o intuito de estabelecer pontes entre o passado e o presente, pretendemos trazer à tona a discussão sobre as disputas pela memória da ditadura, especificamente no que se referem aos lugares (monumentos, viadutos, prédios...) que fazem referência ou apologia ao período da ditadura militarempresarial brasileira (1964-1985).

Os estudos de Maurice Halbwachs sobre memória coletiva apresentam a memória como produtora de coesão social e destaca os aspectos positivos da memória, fundamentando e reforçando sentimentos de pertencimento, assim como as suas fronteiras socioculturais. Nesse processo, ao se referir à memória de um grupo e aos limites de suas memórias coletivas se percebe aquilo que podemos chamar de seletividade da memória, cuja finalidade é a conservação dos grupos. O que estes lembram e o 
que esquecem, de acordo com Halbwachs (2004), está sempre vinculado ao interesse em sua permanência. Por isso, quando fazemos parte de um grupo e pensamos em comum com este grupo, "sob alguns aspectos, permanecemos em contato com esse grupo, e continuamos capazes de nos identificar com ele e de confundir nosso passado com o seu." (HALBWACHS, 2004, p.33)

Desta forma, os grupos tendem a "pretender conservar o passado dentro do presente, ou introduzir o presente no passado" (HALBWACHS, 2004, p.93). Assim, há uma intenção dos grupos de manter em suas memórias o tempo dos acontecimentos em que não ocorreram grandes mudanças que os façam não se reconhecerem como grupos e retirar de suas memórias os acontecimentos que porventura são "incompatíveis" com o seu passado (HALBWACHS, 2004, p.92).

Aquelas lembranças que estão sempre ao nosso alcance são as lembranças "que se conservam em grupos nos quais somos livres para penetrar quando quisermos". (HALBWACHS, 2004 , p. 54) Essas lembranças evocamos com facilidade. Há outro conjunto de lembranças que não evocamos quando queremos. São as lembranças individuais. Essas lembranças são difíceis de alcançar, "são menos e mais raramente acessíveis, porque os grupos que as trariam a nós estão mais distantes; não estamos em contato com eles senão de modo intermitente" (HALBWACHS, 2004, p. 54)

As lembranças, tanto as que evocamos com facilidade quanto as que nos fogem, têm seu suporte no grupo. Portanto, para Halbwachs, toda memória é coletiva e é construída. Assim, "cada memória individual é um ponto de vista sobre a memória coletiva, que este ponto de vista muda conforme o lugar que ali eu ocupo, e que este lugar mesmo muda segundo as relações que mantenho com outros meios". (HALBWACHS, 2004, p.55). Desta forma, para Halbwachs, não existe memória individual. 
O passado comum de um grupo só é acessado na lembrança (estado de consciência individual) na medida em que as questões que separam as pessoas no presente puderem ser esquecidas. Considerando estes aspectos, observamos que o passado é o tempo todo reconstruído, evocado, ora por nós ora pelos grupos aos quais estamos vinculados. No entanto, de uma forma ou de outra, a nossa memória se apóia na memória dos outros e a memória dos outros se apóia em nossa memória.

Por outro lado, Michael Pollak (1989) nos instiga a pensar nas funções da memória a partir de um viés diferente. Salienta que, como discípulo de Durkheim, Halbwachs reforça a função da memória coletiva de manter, conservar e construir bases referenciais capazes de contribuir para a coesão interna de um grupo social. Pollak inclui Halbwachs na tradição dos pensadores de todo o século XIX, ao considerar que a memória nacional é a forma mais completa de memória coletiva. No entanto, o autor não considera que tal processo de construção da memória tenha um aspecto apenas conciliatório e positivo.

Ao considerarmos o processo de negociação da memória nacional dita oficial, a seleção do que deverá ser lembrado e do que deverá ser esquecido passa por um processo de hierarquização de histórias e de desvalorização das memórias de grupos vencidos, excluídos, de minorias, dentre outros. Apesar disso, Pollak (1989) destaca que as memórias subterrâneas, ou seja, aquelas vinculadas às ideias e às histórias marginalizadas dentro de um determinado contexto social, prosseguem em um trabalho e fluxo de subversão contra os aspectos opressivos e uniformizadores da memória coletiva dita oficial. Este trabalho se mantém no nível do "não-dito", no nível do silêncio, de maneira quase imperceptível, despertando na sociedade principalmente em momentos de crise, quase sempre de forma brusca e sobressaltada.

Em seu artigo Memória, Esquecimento, Silêncio (1989), Pollak nos brinda com três exemplos que elucidam muito bem o 
que quer dizer com o conceito de memória subterrânea. O primeiro se refere ao fenômeno do stalinismo na antiga União Soviética e a relação com a memória subterrânea daqueles que sofreram com os crimes praticados por Stalin. O segundo se refere ao silêncio dos deportados após a Segunda Grande Guerra, os quais, por estarem fora de suas redes de sociabilidade, demonstraram dificuldades de integrar suas lembranças na memória coletiva das nações que passaram a viver. E o último exemplo destaca as memórias subterrâneas inerentes aos recrutados da Alsácia, anexada pela Alemanha no decorrer da Segunda Guerra, os quais foram forçados a lutar em favor do exército nazista.

Tais exemplos de memória subterrânea permitiram a Pollak (1989) determinar três aspectos fundamentais das disputas no campo memorialístico: (a) movimentos políticos de transformações necessitam também de mudanças no campo da memória, ou seja, as leituras do passado afetam o cenário político do presente e do futuro; (b) a impossibilidade de se controlar plenamente construções ou mudanças no campo da memória; (c) e que memórias traumatizantes e dissidentes da memória oficial são capazes de sobreviver no nível do "não-dito" durante anos.

As determinações propostas por Pollak (1989), por sua vez, nos permitem propor um passo a mais em sua análise. Percebemos duas esferas básicas que compõe um cenário de disputas no nível político entre memórias. O primeiro campo, que denominamos administração da memória oficial, ligado à memória coletiva, produz e reforça o consenso e a coesão social. Por outro lado, esse campo também generaliza consciente e estrategicamente as lembranças e, dessa forma, produz premeditadamente violências e injustiças com grupos marginalizados. Já o segundo campo, se referem às memórias de resistência e de luta, aquelas que sobrevivem no nível subterrâneo do tecido social, mas que suas fronteiras de 
esquecimento e lembrança estão em perpétuo deslocamento, situação que contribui para impedir a administração plena da memória oficial.

A memória é seletiva, não é neutra e está permeada pelo poder, por isso, negar, negligenciar e esquecer são componentes da memória. Alguns fatos, contextos, lugares, instituições e classes precisam ser cautelosamente rememorados pela memória "oficial", enquanto outros precisam ficar eternamente embaixo do tapete (FERRAZ, 2007). As políticas de conciliação, características das políticas estatais da América Latina hoje, pautam-se principalmente pelo embate entre as memórias subterrâneas e as memórias produzidas pelo Estado.

Neste artigo, discorreremos sobre as políticas de preservação dos lugares de memória, na perspectiva de Pierre Nora (1990), salientando as disputas entre o Estado e os movimentos sociais. A cidade do Rio de Janeiro é marcada por inúmeros lugares que fazem alusão ao golpe e à ditadura militarempresarial. São monumentos, bustos, praças, viadutos, logradouros, prédios. Estes lugares foram erguidos durante o governo ditatorial e até hoje ainda permanecem inalterados. Pretendemos pensar o lugar político destes lugares de memória a partir das querelas em torno da patrimonização de alguns espaços e prédios, fazem apologia ao golpe e à ditadura, na cidade do Rio de Janeiro. A política que tem sido efetuada até agora pelo Estado pode ser definida como conciliatória. Não obstante, os movimentos sociais reclamam a inserção de suas vozes nestes lugares, considerando-as, silenciadas ou esquecidas. Interessa-nos analisar estas disputas e as seus reflexos na sociedade.

\section{Demandas dos Movimentos Sociais}

Aos lugares onde repousam as evidências empíricas da memória coletiva de um grupo social específico, Pierre Nora (1993) denomina lugares de memória. Neles, a memória já não se 
apresenta para o grupo como algo espontâneo. Só consagramos lugares quando não estamos mais vivendo a experiência em comum com um grupo. "Se habitássemos ainda nossa memória não teríamos necessidade de lhe consagrar lugares." (NORA, 1993, p. 8) Nestes lugares se incluem as tradições, os costumes, o folclore, a música, o patrimônio arquitetônico, os monumentos, as leis, dentre outros exemplos.

A coligação que levou Lula e Dilma ao poder, mantevese durante treze anos (2003 a 2016) e reuniu mais de uma dezena de partidos ${ }^{4}$, conduziu articuladamente a política de preservação da memória de ditadura. Nada deixou de ser pensado. Esta coligação buscou reconstruir uma memória que tem somente o passado como referência, completamente ajustada a uma política de conciliação. (FERRAZ, 2014) Essas memórias foram meticulosamente selecionadas de forma a não colocar em xeque o poder do capital e do próprio Estado.

No entanto, em se tratando de memória, o jogo de sentidos, inevitavelmente, produz nuanças, zonas cinzentas, rotas que escapolem à orquestração minuciosamente planejada pelo Estado. Sem dúvida, fatos, eventos, dores, acontecimentos que se situam no universo do indizível à nova memória nacional tentarão ser jogados debaixo do mesmo tapete de algumas memórias da escravidão e da ditadura Vargas.

A política de conciliação tem como principal meta produzir esquecimento e silêncio, mais do que memória. $O$ controle do esquecimento e do silêncio pode produzir novas tiranias. O grande problema não se coloca em termos de existir ou não memória, de se fazer ou não seleção de memórias, mas do Estado se colocar como o controlador da memória. Do Estado definir não somente o que se deve recordar, senão, também, como se deve recordar.

\footnotetext{
${ }^{4}$ Os partidos da coligação petista para presidência, no segundo turno, em 2002, foram $\underline{\mathrm{PT}}, \underline{\mathrm{PL}}, \underline{\mathrm{PCdoB}}, \underline{\mathrm{PPS}}, \underline{\mathrm{PDT}}, \underline{\mathrm{PTB}}, \underline{\mathrm{PSB}}, \underline{\mathrm{PGT}}, \underline{\mathrm{PSC}}, \underline{\mathrm{PTC}}, \underline{\mathrm{PV}}, \underline{\mathrm{PMN}}, \underline{\mathrm{PHS}}$ e $\underline{\mathrm{PCB}}$.
} 
Os movimentos sociais, dentre eles destacamos o Grupo Tortura Nunca Mais-RJ, defendem que esta memória, dita oficial, contemple, também, outras falas, outras interpretações e inclua pessoas, grupos e acontecimentos que foram silenciados. Que tornem públicas as experiências traumáticas daqueles que entregaram as suas vidas à causa política. Que esta memória nos relembre as propostas que foram abortadas por serem perigosas, por proporem mudanças sociais necessárias para a construção de uma sociedade mais igualitária.

Estes grupos entendem que é preciso lembrar para que jamais se esqueça. Defendem que a reescrita deste passado, incluindo as diferenças, permite à sociedade repensar o seu presente e o seu futuro. Porém, mais que isto, permite reencontrar este passado, percorrer seus caminhos tortuosos, reencontrar nele um sentido de pertencimento coletivo.

Ao contrário, o soterramento da memória dos grupos implicados na luta política, por meio do desaparecimento de muitos corpos, rapto dos arquivos, negação da tortura, desqualificação intelectual e moral dos opositores, afirma, na consciência coletiva, a evidência de que não se deve buscar formas alternativas de vida social digna.

A elaboração coletiva deste passado, ao contrário, recria sonhos e esperanças, resistências e rotas de fuga.

Algumas questões polêmicas nos atravessam diariamente. As novas gerações têm uma informação muito mal elaborada sobre o que ocorreu. Nos bancos escolares esta história não é contada de forma íntegra, clara e elucidativa, considerando o lado dos oprimidos.

Assim, as dimensões da luta contra o esquecimento e o silêncio, podem ser sintetizadas a partir dos movimentos dos familiares de mortos e desaparecidos, que ainda na década de 1970, saem dos seus espaços de dor privados e iniciam as denúncias e as buscas por seus familiares. Em pouco tempo, a este movimento juntou-se o movimento de mulheres pela anistia 
(1974). O movimento pela Anistia ampliou-se rapidamente no Brasil. Entre 1978 e 1979, os Comitês Brasileiros pela Anistia (CBAs) já se consolidava em muitas capitais brasileiras. A precária Lei de Anistia (1979) acabou desmantelando os Comitês Brasileiros de Anistia e pouco serviu para a busca dos atingidos, uma vez que apenas oferecia aos familiares um atestado de Morte presumida ou de paradeiro ignorado. No vácuo deixado pelo desmantelamento dos CBAs, a Comissão de Familiares de Mortos e Desaparecidos Políticos (CFMDP), com sede em São Paulo, mas articulada em todo o território nacional (inclusive com grande apoio do Grupo Tortura Nunca Mais-RJ), se reestrutura de maneira independente e é responsável por significativos avanços, dentre eles a Lei 9140/1995, denominada Lei dos Desaparecidos Políticos. As reivindicações elaboradas pela CFMDP ainda hoje são o principal ponto de pauta dos movimentos sociais, dentre os quais, o Grupo Tortura Nunca Mais-RJ. Essas reivindicações são:

a) O esclarecimento detalhado (como, onde, porque e por quem) das mortes e dos desaparecimentos ocorridos;

b) O reconhecimento público e inequívoco pelo Estado de sua responsabilidade em relação aos crimes cometidos;

c) $\mathrm{O}$ direito de as famílias enterrarem condignamente seus entes queridos, visto caber ao Estado, e não a eles, a responsabilidade pela localização e identificação dos corpos;

d) A inversão do ônus da prova: é dever do Estado, e não dos familiares, diligenciar as investigações cabíveis, buscando provar não ser ele o responsável direto pelos assassinatos;

e) A abertura incondicional de todos os arquivos da repressão sob jurisdição da União; 
f) O compromisso de não nomear e de demitir de cargos públicos todos os envolvidos nos crimes da ditadura;

g) A inclusão de todos os militantes assassinados por agentes do Estado no período entre 1964 e 1985;

h) A indenização como direito e, principalmente, efeito de todo o processo de luta.

Passados trinta e dois anos do fim da ditadura militar estas demandas ainda permanecem, com poucas mudanças. 0 que o Estado tem feito em relação à memória deste período é extremamente precário. Em relação aos lugares de memória (NORA, 1993), as marcas da presença do terror do Estado ou do fortalecimento do golpe permanecem nos espaços da cidade. Nas ruas, nos viadutos, nas pontes e nos prédios públicos, enfim, a memória do terror permanece viva no patrimônio da cidade do Rio de Janeiro e de inúmeras outras capitais do país.

\section{Políticas de Preservação do Patrimônio}

Por patrimônio compreende-se uma multiplicidade de formas que a todo tempo têm seus sentidos reapropriados, como assinala Henri-Pierre Jeudy (1990). "Portanto trata-se, ao mesmo tempo, de um reconhecimento dessa pluralidade dos elementos que constituem o patrimônio, e de uma reflexão coletiva acerca dos movimentos das memórias e das identidades." (JEUDY, 1990, p. 11)

A política de preservação da memória e do patrimônio deve ser entendida como o resultado de uma "prática social e cultural de diversos e múltiplos agentes" (FÉNELON, 1992, p. 31), e mais do que isso, a memória é política, por excelência. Portanto, a noção de patrimônio, tal qual a compreendemos na contemporaneidade, engloba uma discussão mais ampla, em toda a sociedade, sobre o que "deve" e "pode" ser memorável. 
Não deve ser restrita aos técnicos a tarefa de preservar a memória e o patrimônio.

Porém, é necessário que esta memória colabore positivamente para a reconstrução dos sujeitos envolvidos. Esta também deveria ser a função das Leis e dos Decretos, enfim, das políticas de preservação da memória e do patrimônio.

O que se verifica é que, na maioria dos casos, os atores que lutaram contra a ditadura não se sentem representados pela memória nacional, pelos monumentos, pelas Leis e Decretos, entendidos no contexto desta memória. Monumentos que fazem alusão ao golpe, tais como ruas, viadutos, logradouros, praças estão espalhados pelas cidades brasileiras. Demarca-se, portanto, um cenário de disputa entre os atingidos pela ditadura militarempresarial brasileira e a ação conciliadora do Estado.

No campo específico da política museal, Santos (2014), inferindo sobre Huyssen, assinala que estas disputas inserem-se na lógica da "legitimação ideológica do capitalismo e pela comodificação da arte", portanto, fazem parte do "processo de modernização, da economia de mercado e das novas políticas culturais". (SANTOS, 2014, p. 50)

No Rio de Janeiro, em vários locais da cidade (Centro, Zonas Sul, Norte e Oeste), se verificam estes registros do terror do Estado. Em um pequeno percurso pela cidade há um número imenso de ruas, avenidas, escolas públicas e praças que homenageiam ditadores e as memórias que envolvem as suas atividades de terror.

A memória histórica "oficial" é um lado perverso de nossa história, produzida pelas práticas dominantes para apagar os vestígios que as classes populares e os opositores vão deixando ao longo de suas experiências de resistência e luta, num esforço contínuo de exclusão dessas forças sociais como sujeitos que forjam a história. Pretendem com isso desconhecer, desfigurar e distorcer os embates 
reais dos "vencidos", como se estes não estivessem presentes no cenário político. (DOSSIÊ DE MORTOS E DESAPARECIDOS, 1995, p. 23)

A memória que se coloca como oficial, monumentalizada e patrimonializada pelo Estado, produz modos eficientes de coerção e de anulação de um tipo específico de memória coletiva. A vontade de verdade, como assina Foucault (2001, p. 17), "apóia-se sobre um suporte institucional (...) pelo modo como o saber é aplicado em uma sociedade, como é valorizado, distribuído, repartido e de certo modo atribuído".

A maquinaria é articulada para

(...) excluir todos aqueles que, ponto por ponto, em nossa história, procuraram contornar essa vontade de verdade recolocá-la em questão contra a verdade, lá justamente onde a verdade assume a tarefa de justificar a interdição e definir a loucura. (FOUCAULT, 2001, p. 17)

A vontade de verdade produz o discurso que diz, não residindo mais "no que era o discurso, ou no que ele fazia". (FOUCAULT, 2001, p. 15) Assim, o Estado diz. O que estava em pauta para os militantes do pré-64 eram as reformas de base (reforma agrária, reforma fiscal, reforma educacional, administrativa, dentre outras). Somente no segundo momento da luta os militantes queriam o fim de um poder ilegal, imposto pelo golpe, o fim da ditadura e o retorno da normalidade democrática.

No entanto, muitos livros de História reduzem a luta política à luta contra a ditadura. Esta memória construída pelo estado ditatorial e reproduzida em muitas escolas denomina de "revolução democrática" o golpe militar-empresarial. A data de 10 de abril (Dia da Mentira, no Brasil) como marco inicial de 
instauração da ditadura, disputa, na memória coletiva, com o 31 de março, data definida pelos militares e pelo Estado, ainda hoje.

Cuidadosamente planejada, esta data foi evocada no uso cotidiano até que de farsa se transforme em hábito e de hábito reabilite-se à memória nacional. Foi na intenção de promover esta recriação da memória nacional que o viaduto construído em 1973 (em plena ditadura), que liga a Zona Norte à Zona Sul da Cidade do Rio de Janeiro, foi nomeado Viaduto 31 de Março (foto), localizado no bairro do Catumbi, bairro proletário da Zona Central do Município do Rio de Janeiro. Para os ditadores, o dia 31 de março representa o dia da tomada do poder, o dia da vitória contra o inimigo interno.

Este viaduto está situado entre o Sambódromo (Passarela do Samba - onde as escolas de samba desfilam) e o Palácio Guanabara, sede do governo do Estado do Rio de Janeiro (residência oficial do Governador do Estado).

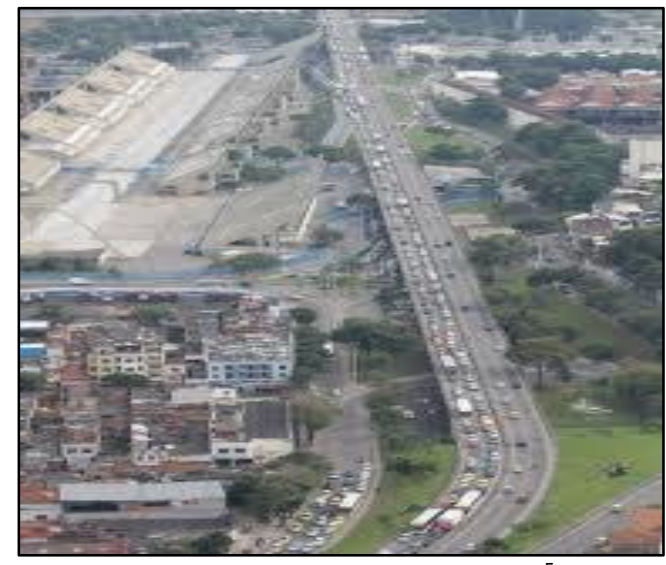

IMAGEM 1: Viaduto 31 de março ${ }^{5}$

\footnotetext{
${ }^{5}$ Fonte da imagem: http://odia.ig.com.br/2013-05-27/asfalto-cede-no-tunelsanta-barbara-e-congestiona-o-transito-ate-o-centro.html. Acessado em 14/12/2014.
} 


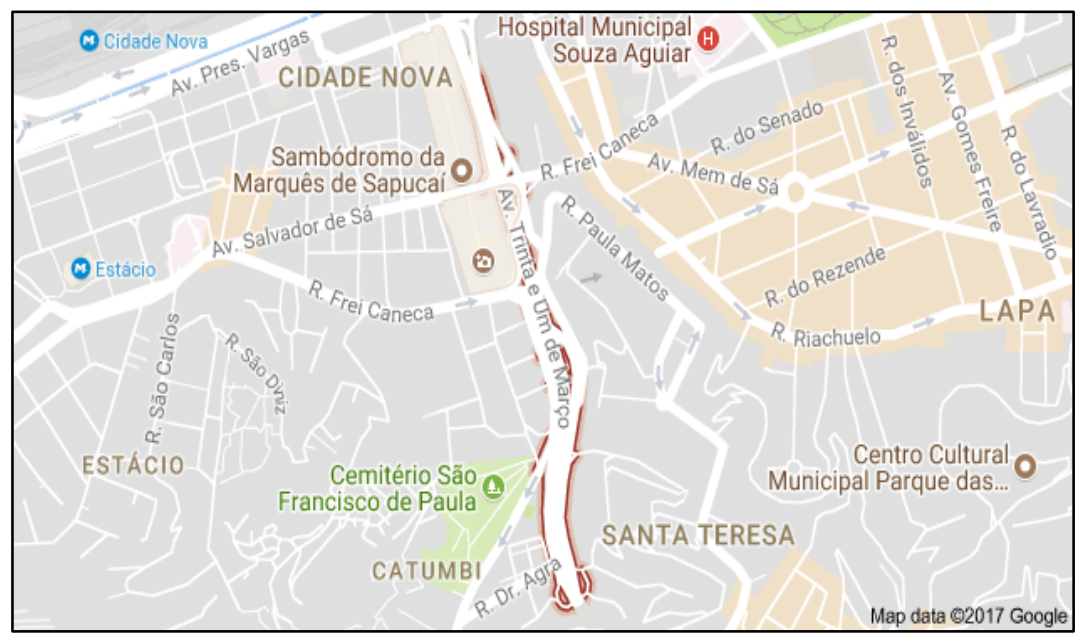

IMAGEM 2: Mapa do Viaduto 31 de Março, também conhecida como Avenida 31 de Março ${ }^{6}$

A ação do Estado não se limita somente a construir o seu discurso sobre os eventos. Interessa-lhe, também, quando necessário, silenciar, por meio da inércia, qualquer ação que possa causar conflitos à sua vontade de verdade. O processo de recusa de reconhecimento e de produção de esquecimento produz um dizer muito sutil.

A decomposição de alguns lugares é um ato transbordante de sentidos. O prédio do antigo Departamento de Ordem Política e Social (DOPS), localizado na Rua da Relação, 40, na Lapa, Centro da cidade do Rio de Janeiro (foto) está em pleno estado de decomposição. Este prédio funcionou como prisão e centro de tortura durante o regime militar-empresarial. Os

\footnotetext{
${ }^{6}$ Fonte da imagem:

https://www.google.com.br/search?rlz=1C1CAFB enBR662BR665\&q=viaduto+3 $1+$ de+mar\%C3\%A7o+ri\&oq=viaduto $+31+$ de + mar\%C3\%A7o+ri\&gs I=psyab.3...1389435.1398259.0.1399262.0.0.0.0.0.0.0.0..0.0....0..1.1.64.psyab..0.0.0.- $5 \mathrm{DCdCl} 2 \mathrm{c} 8$, acessado em 10/08/2017.
} 
movimentos sociais reivindicam, há décadas, transformar este prédio em Centro de Resistência.

Inicialmente, este prédio era patrimônio da União e alojava a Repartição Central de Polícia (1910), em estilo eclético, projetado pelo famoso arquiteto Heitor de Mello. Ele guarda em suas memórias os mais variados momentos de violência do Estado no Brasil. No início do século $X X$, serviu de centro de repressão da vadiagem, da capoeira, das religiões afrodescendentes. Quando a Capital do Brasil saiu do Rio de Janeiro, transferindo-se para Brasília, em 1961, este prédio foi entregue ao governo do Estado da Guanabara.

Na ditadura Vargas - Estado Novo - (1937-1945), este prédio pertenceu à Delegacia Especial de Segurança Política e Social (DESPS), de 1933 a 1944, onde Luiz Carlos Prestes e Olga Benário foram presos. Durante a ditadura militar-empresarial (1964- 1985), sediou o "Departamento de Ordem Política e Social do Estado da Guanabara (DOPS-GB), de 1962 a 1975, e o Departamento Geral de Investigações Especiais (DGIE), de 1975 a 1983" (Iser, s/d, p.1) ${ }^{7}$

Este prédio é cenário de uma grande disputa entre a Secretaria de Polícia e os movimentos sociais que lutam pela preservação da memória da ditadura brasileira. O objetivo dos movimentos sociais é instituir neste lugar um espaço de ação museal que inscreva a memória dos vencidos, dos ativistas que por ali passaram, que foram detidos, torturados e vivenciaram o terror do Estado.

A dificuldade de fazer qualquer uso deste espaço reside, também, no alto custo de sua restauração. Este prédio encontrase hoje em escombros e os arquivos ali depositados estão completamente destruídos. O desaparecimento de um prédio

\footnotetext{
${ }^{7}$ Fonte:

http://www.cartografiasdaditadura.org.br/files/2014/03/Departamento de Or dem Pol\%C3\%ADtica e Social-DOPS 3.pdf, consultado em 10/08/2017.
} 
deste porte, a indiferença do estado diante da sua esplêndida arquitetura nos diz muito. Nada é por acaso. Há uma recusa de reconhecimento deste espaço que é política, antes de tudo.

Tombado pelo Instituto Estadual do Patrimônio Cultural (INEPAC), o prédio, hoje sob a administração da Polícia Civil, encontra-se em péssimo estado de conservação, com arquivos ainda não identificados em deterioração, o que evidencia a destruição e o abandono do poder público para com o patrimônio histórico. (Iser, s/d, p. 2$)^{8}$

Há décadas, a historiadora Jessie Jane, professora de História da UFRJ e ex-diretora do APERJ e os militantes do Grupo Tortura Nunca Mais-RJ, elaboraram um Plano de Ação para fazer deste lugar um espaço de Memória da Resistência à ditadura.

É com a intenção de preservação deste espaço que, desde 2010, quando este prédio fez 100 anos, se uniram diversos coletivos e movimentos sociais no sentido de sensibilizar os órgãos públicos e a sociedade civil a fim de fazer dele o Museu da Resistência do Rio de Janeiro, ligado ao Arquivo Público do Estado do Rio de Janeiro (APERJ). Essa intervenção da sociedade civil neste espaço recebeu o nome de "Ocupa DOPS".

Atualmente, o Prédio do DOPS, como é conhecido pelos movimentos sociais, pertence à Secretaria de Segurança, sendo administrado pela Polícia Civil. Esta corporação também reivindica que neste espaço seja criado o Museu Histórico da Polícia.

${ }^{8}$ Idem 


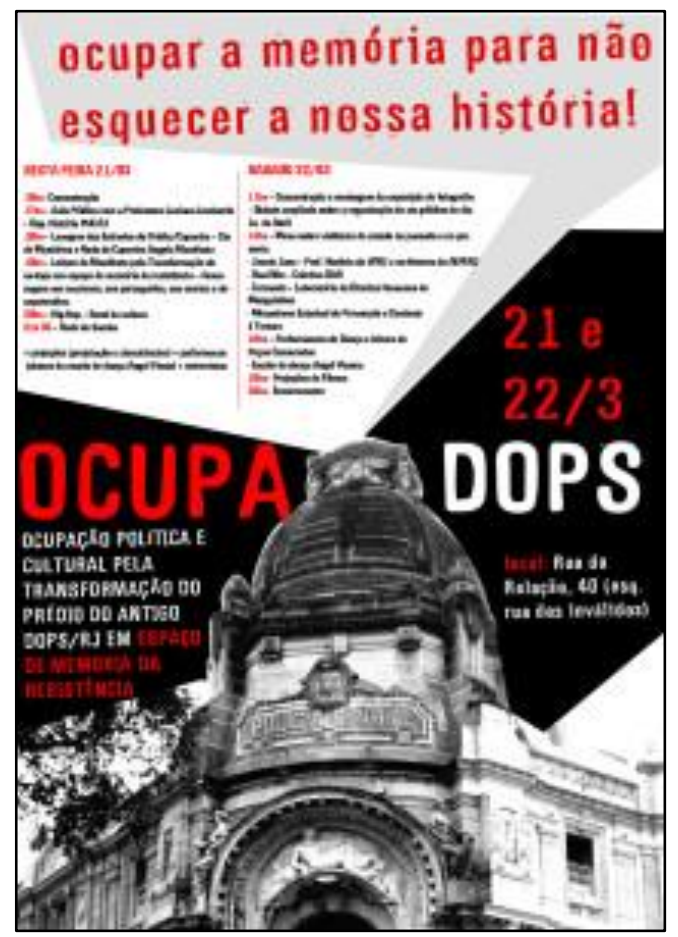

IMAGEM 3: Cartaz do Evento Ocupa DOPS.

Dado o impasse, o governador Sérgio Cabral (2007-2010 e 2011-2014) sugeriu que o prédio abrigasse as duas entidades.

A criação do museu no prédio era uma reivindicação antiga de militantes pelos direitos humanos. Já estiveram presos na antiga sede do Dops personalidades como Luiz Carlos Prestes, Olga Benário e Mário Lago. A Polícia Civil do Rio de Janeiro, entretanto, briga pela posse do espaço, para que ele seja transformado em um museu da corporação.

Para Cabral, um projeto não invalida o outro. "É perfeitamente possível eles conviverem [os dois 
museus]", disse o governador, minimizando a polêmica da destinação do prédio. "Ninguém é contra a memória, mas a memória mais importante é que aquele prédio foi local de torturas de presos políticos e processos covardes." - Do UOL, no Rio 08/05/2013. ${ }^{9}$

Na proposta conciliadora do ex-governador, no andar superior ficaria o Museu Histórico da Polícia e no andar inferior abrigaria - Museu da Resistência. Esta proposta foi rejeitada pelas entidades de defesa dos direitos humanos, considerando a impossibilidade de manter no mesmo espaço a memória do oprimido e do opressor. Até hoje o prédio do DOPS-RJ encontrase sem nenhuma destinação e em ruínas.

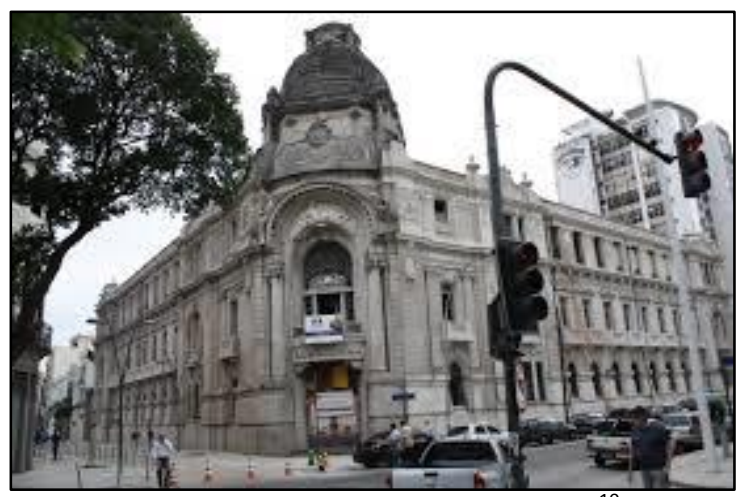

IMAGEM 4: Antigo Prédio do DOPS/RJ ${ }^{10}$.

Outro cenário de disputas entre o poder público e os movimentos de defesa dos direitos humanos refere-se ao prédio

\footnotetext{
${ }^{9}$ https://noticias.uol.com.br/cotidiano/ultimas-noticias/2013/05/08/cabralanuncia-instalacao-de-museu-da-ditadura-em-antigo-predio-dodops.htm?cmpid=copiaecola, consultado em 11/08/2017. ${ }^{10}$ Fonte da imagem: http://www.cartografiasdaditadura.org.br/mapa/dops-rjmemoria-historia-e-resistencia/. Acessado em 14/12/2014.
} 
do antigo Destacamento de Operações de Informações do Centro de Operações de Defesa Interna (DOI-CODI), onde funcionava o Quartel do 1 을 Batalhão de Polícia do Exército, localizado no bairro da Tijuca, Rio de Janeiro. Este local também funcionava como centro de tortura durante a ditadura brasileira.

Assim como no caso do prédio do DOPS, os movimentos sociais lutam há décadas para transformar o local em Centro de Resistência. Como alternativa, a Comissão Estadual da Verdade do Rio de Janeiro construiu, de costas para o prédio, o Busto de Rubens Paiva, desaparecido político, que foi visto pela última vez neste local.

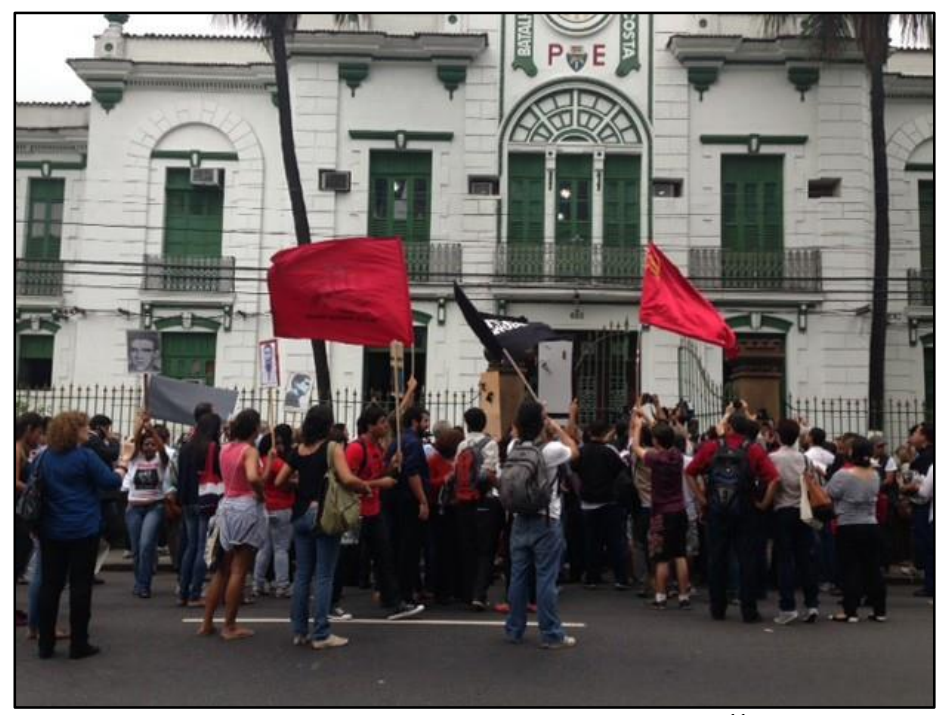

IMAGEM 5: Antigo prédio do DOI-CODI/RJ ${ }^{11}$.

\footnotetext{
${ }^{11}$ Fonte da imagem: http://g1.globo.com/rio-dejaneiro/noticia/2013/09/comissao-da-verdade-visita-local-onde-ficava-o-doicodi-no-rio.html. Acessado em 14/12/2014.
} 


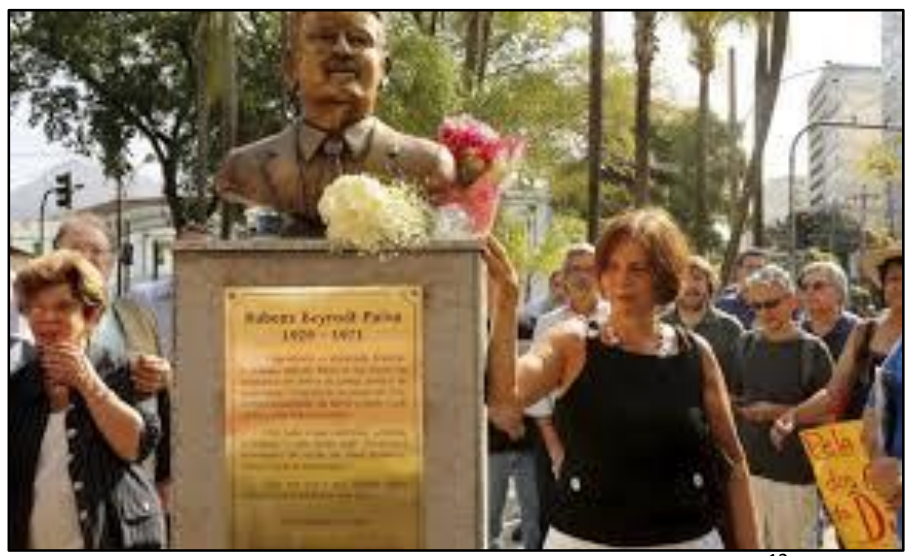

IMAGEM 6: Inauguração do Busto de Rubens Paiva ${ }^{12}$

À direita do busto de Rubens Paiva, posicionado de costas para o antigo DOI-CODI, está sua filha, Vera Paiva.

Outra reivindicação dos movimentos sociais é a mudança de nome da ponte que liga as cidades do Rio de Janeiro e Niterói, o início de sua construção foi em 1969 e o término foi em 1974. Construída durante a ditadura militar-empresarial, esta ponte recebe o nome de Ponte Presidente Costa e Silva. No governo deste presidente ocorreram inúmeras violações aos direitos humanos, tais como exílios, prisões, desaparecimentos, torturas e mortes. Além disso, foi em seu governo que foi instituído Ato Institucional número 5, conhecido como Al-5. O Al5 data de 13 de dezembro de 1968 e pode ser considerado como o golpe mais duro da ditadura brasileira ${ }^{13}$. Essa medida legitimou definitivamente o terror do Estado, que já vinha sendo praticado desde o primeiro dia do regime, referendando ainda mais as

\footnotetext{
${ }^{12}$ Fonte da imagem: http://oglobo.globo.com/brasil/comissao-daverdade/busto-de-rubens-paiva-inaugurado-em-frente-ao-antigo-doi-codi13923550. Acessado em 14/12/2014.

${ }^{13}$ D'ARAÚJO, Maria Celina. O Al-5. Disponível em: http://cpdoc.fgv.br/producao/dossies/FatosImagens/Al5. Acessado em 14/12/2014.
} 
práticas de tortura e perseguições adotadas como ferramentas de governo desde então.

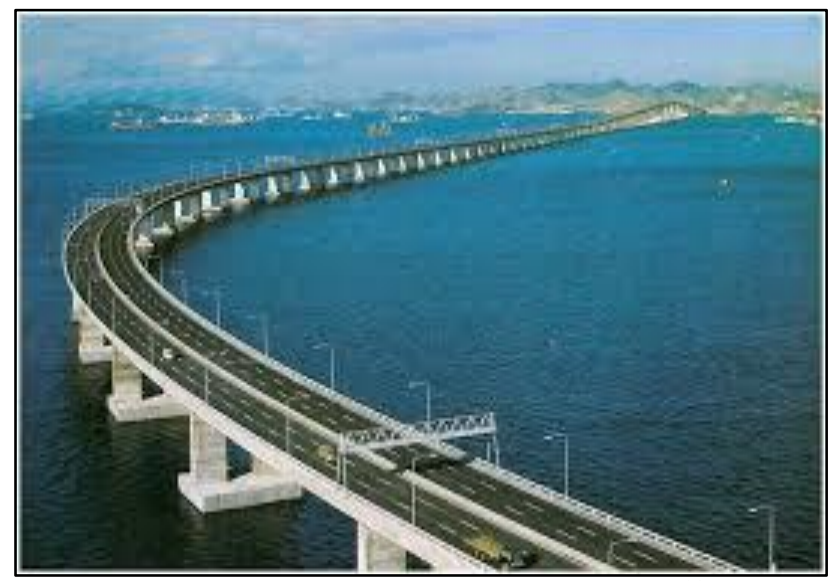

IMAGEM 7: Ponte Presidente Costa e Silva. ${ }^{14}$

Tramita na Câmara dos Deputados um Projeto de Lei, de 07 março de 2012, de autoria do Deputado Federal Francisco Alencar (PSOL-RJ), que propõe a mudança de nome para Ponte Herbert de Souza ${ }^{15}$. Herbert de Souza, mais conhecido como Betinho, foi um sociólogo brasileiro e ativista pelos direitos humanos. Betinho sofreu diretamente durante a ditadura militarempresarial, sendo obrigado a se exiliar primeiro no Chile e depois, com a instauração da ditadura de Pinochet naquele país, se exilou no Canadá e no México antes de voltar ao Brasil. Este projeto foi aprovado na Comissão de Constituição e Justiça e de Cidadania (CCJC) da Câmara dos Deputados e está dependendo

\footnotetext{
${ }^{14}$ Fonte da imagem: http://pt.slideshare.net/lowrraynyfranchesca/projetounificado-I-1-etapa-tipos-de-pontes-existentes. Acessado em 14/12/2014.

${ }^{15}$ Fonte de consulta do Projeto Lei 3388/2012: http://www.camara.gov.br/proposicoesWeb/fichadetramitacao?idProposicao $=5$ 36329. Acessado em 14/12/2014.
} 
de votação no Plenário, segundo informação da assessoria do deputado Chico Alencar, em 10 de agosto de 2017.

Este projeto é assinado por muitos movimentos sociais, dentre os quais, o Centro de Teatro do Oprimido - CTO, o Coletivo RJ Memória, Verdade e Justiça, o Grupo Tortura Nunca Mais-RJ, o Instituto Brasileiro de Análises Sociais e Econômicas IBASE, o Instituto de Defensores de Direitos Humanos - IDDH, o Instituto de Estudos e Religião - ISER, o Instituto Frei Tito de Alencar, a Justiça Global e a Rede de Comunidades e Movimentos contra a Violência.

A base do argumento deste PL está definida pelo Terceiro Plano Nacional de Direitos Humanos (PNDH-3), criado pelo governo Luiz Inácio Lula da Silva, em dezembro de 2009. O Eixo 6, Diretriz 25 do PNGH-3, prevê que "não mais sejam homenageados, a partir do batismo de logradouros públicos com seus respectivos nomes, indivíduos que notadamente tenham cometido crimes e perpetrado violações dos direitos humanos no período da Ditadura Civil Militar de 1964-1985"16.

O Projeto Lei 3388/12 assinala a impossibilidade da manutenção do nome de Ponte Presidente Costa e Silva a esta ponte pelo fato deste presidente ter sido um dos "artífices do golpe militar, responsável por momentos dos mais sombrios da história brasileira como o que se inicia com a edição do famigerado Ato Institucional no 5 (Al-5)." (PL 3388/2012)

Não há nenhuma possibilidade de separarmos 0 passado e do presente. queiramos ou não, o tempo, como multiplicidade e duração (BERGSON, 1999) recobra de cada um de nós e também da sociedade a inscrição de falas silenciadas por décadas, outras por milhares de anos.

\footnotetext{
${ }^{16}$ http://www.pndh3.sdh.gov.br/portal/sistema/navegacao-eixo/eixo/6\#, consultado em 10/08/2017.
} 
Há várias maneiras de narrar a história de um país. Uma visão sempre esquecida, conhecida como a "ótica dos vencidos", é aquela forjada pelas práticas dos movimentos sociais populares, nas suas lutas, no seu cotidiano, nas suas resistências e na sua teimosia em produzir outras maneiras de ser, outras sensibilidades, outras percepções. Práticas que recusam as normas pré-estabelecidas e instituídas e que procuram de certa forma construir outros modos de subjetividades, outros modos de relação com o outro, outros modos de produção, outros modos de criatividade. (DOSSIÊ DE MORTOS E DESAPARECIDOS, 1995, p. 23)

Estas disputas pelas memórias, como vimos, têm contornos cronológicos, legais, patrimoniais, políticos e psicossociais. Estão permeadas de poder. Já não se pode ingenuamente imaginar que não há relação entre a permanência da memória do golpe e da ditadura militar-empresarial brasileira nos espaços da cidade e a dificuldade de registrar uma outra memória, que contemple a história dos que lutaram por uma sociedade que afirme a vida digna e igualitária. Queiramos ou não por onde passamos diariamente, da Zona Norte à Zona Sul da cidade do Rio de Janeiro, - e no Brasil inteiro esta realidade é exatamente igual - vemos os nomes dos militares golpistas, as suas "grandes obras" e as datas "comemorativas" que afirmaram o seu poder opressor. Não são casos isolados. Não são coincidências. É uma política exercida para a naturalização e perpetuação do poder, como afirma Mario Chagas:

Indicar que as memórias e os esquecimentos podem ser semeados e cultivados corrobora a importância de se trabalhar pela desnaturalização desses conceitos e pelo entendimento de que eles resultam de um processo de construção que 
também envolve outras forças, como por exemplo: o poder. O poder é semeador e promotor de memórias e esquecimentos. (CHAGAS, 2009, p. 2)

A política de conciliação, exercida pelos governos municipal, estadual e federal, conduzida pela coalizão petista (2002-2016), embora tivesse conduzido alguns avanços no que se referem às políticas sociais, manteve intactos muitos pactos estabelecidos na negociação com os militares e com o empresariado em relação às políticas de memória da ditadura. Os arquivos do Exército, da Marinha, da Aeronáutica e da Polícia Investigativa (P2) permanecem fechados.

A Lei de Anistia, criada pelos parlamentares de esquerda, todas as vezes em que foi colocada em votação, foi boicotada pelos parlamentares aderentes ao regime militar. A Lei de Anistia (Lei número 6.683/1979) que passou a vigorar e que permanece até hoje com a mesma redação, foi criada pelos militares e aprovada pelos deputados aderentes ao governo militar-empresarial, os parlamentares do movimento ${ }^{17}$ denominado Aliança Renovadora Nacional $\left(\operatorname{ARENA}^{18}\right.$ ), que tinham a maioria no Congresso. Muitos parlamentares do movimento de esquerda denominado Movimento Democrático Nacional

${ }^{17}$ O Ato Institucional número 2 (Al-2, de 1966) extinguiu os partidos políticos no Brasil. Por isso, o arranjo possível para que o Congresso funcionasse, aparentando um clima de normalidade democrática, foi denominar de movimento os dois grupos políticos que faziam parte do Legislativo. Nascia, portanto a ARENA e o MDB. Nestes dois grupos gravitavam membros dos extintos partidos políticos.

18 Nesta época, a Aliança Renovadora Nacional (ARENA) aglomeravam os parlamentares de direita, ligados aos militares. Este grupo controlou o Congresso Nacional durante todo o período da ditadura. Eles eram maioria e por isso aprovavam todas as demandas o que o governo militar propunha. 
$\left(\mathrm{MDB}^{19}\right)$ tiveram seus mandatos cassados. A ARENA tinha maioria para aprovar o que o governo militar propusesse.

Na esteira dessas negociações, de ambos os lados, a Lei de Anistia (dos militares) passou a ser interpretada como uma lei que serviria para anistiar os dois grupos: militares e militantes. A leitura de que os crimes conexos eram relacionados aos crimes que os militares cometeram em decorrência da luta com os militantes abriu a possibilidade de perdão para os crimes de lesa-humanidade cometidos pelo Estado brasileiro, tais como o de tortura, seqüestro e execução. (FERRAZ, 2013, p. 36)

Outra questão que permanece com inúmeras lacunas em relação à memória deste período refere-se à contagem dos mortos e desaparecidos. Oficialmente, são considerados desaparecidos são somente 170 pessoas, denominadas militantes. Inúmeros camponeses, indígenas, crianças, operários, pobres, negros, gays, enfim, uma parte bastante considerável da sociedade brasileira continua anonimamente desaparecida, desde 1964 até hoje. Mesmo assim, as pesquisas nos cemitérios, necrotérios, locais de massacre coletivo de militantes, como ocorreu na região do Araguaia, em busca desses 170 desaparecidos, ainda são muito precárias.

Todas essas questões inconclusas respondem à dificuldade de eternizar a memória deste período. Como transformar em memória o que ainda não foi elaborado pela sociedade? O período da ditadura militar-empresarial brasileira ainda permanece vivo, ardente e silencioso. Não há memória por

19 MDB era o movimento de esquerda, que tinha minoria no Congresso Nacional. 
que sequer é possível construir uma narrativa minimamente coerente, inclusiva e respeitosa com uma parcela imensa da sociedade brasileira.

\section{Conclusão}

O resultado mais cruel desta conciliação, operada pelos governos pós-ditadura, está na perpetuação de uma política de extermínio, de desaparecimentos, de perseguições, sem que se faça uma leitura crítica sobre o que ela representou e ainda representa para a sociedade.

As lições do passado de terror não podem ser analisadas apenas por sua relação com o passado, "mas, somente em razão de nossas conviç̧ões presentes, morais e políticas", como salienta Todorov (2002, p. 198). A esta posição soma-se outra, do mesmo autor, em inferência à Primo Levi: "Um oprimido pode tornar-se um opressor. E com frequência se torna". (TODOROV, 2002, p. 196)

O 1ㅇ de abril e o 31 de março são datas disputadas até hoje. A Ponte Presidente Costa e Silva e o Viaduto 31 de março, assim denominados na época da ditadura, permanecem até os dias atuais. A cínica interpretação da Lei de Anistia, que equipara, em níveis legais, a ação do Estado e a ação dos militantes, sob o pretexto de serem crimes conexos, não nos deixa enganados sobre o propósito político desta conciliação.

As ações conservadoras, feitas em nome da governabilidade, tem funcionado como um divisor de águas entre os movimentos e grupos que lutam por uma outra memória da ditadura. Muitos grupos aderiram ao discurso governista e isso causou e causa uma imensa divisão entre eles.

As ações políticas governamentais que visam o consenso, esquecendo ou silenciando muitas pessoas, fatos e lugares são questões que devem ser questionadas. A relação 
direta entre as opressões do passado e do presente são questões imprescindíveis para uma mudança política em relação à memória do terror do Estado brasileiro. Essas questões expressam as disputas presentes no cenário nacional, nestes cinquenta anos, desde o golpe, em 1964.

Esses nomes, monumentos, pairam numa memória que ainda está muito viva. Talvez, a maior dificuldade de monumentalizar estes espaços repousa justamente no fato de que ainda não se pode falar de memória quando os acontecimentos estão em voga.

Mortes, torturas, desaparição forçada, prisões, ocultação de cadáver, estão presentes em nosso cotidiano. Todos os dias o terror do Estado se manifesta na sociedade brasileira, principalmente em relação às classes populares, aos gays, aos negros. Transformar em monumento, museu, espaço museal é também denunciar, marcar politicamente um lugar de fala, o lugar da afirmação de uma outra história. Não se pode estabelecer um lugar do passado que não passou. Não se pode falar da musealização de uma política de terror do Estado sem assinalar este terror que ainda se faz presente.

\section{Referências Bibliográficas}

BERGSON, Henri. Matéria e Memória: Ensaio sobre a relação do corpo com o espírito. São Paulo: Martins Fontes, 1999.

CHAGAS, Mário. Memória e poder: dois movimentos. Cadernos de Sociomuseologia, [S.I.], v. 19, n. 19, june 2009. ISSN 1646-3714. Disponível em: $<$ http://revistas.ulusofona.pt/index.php/cadernosociomuseologia/article/view/ 367>. Acesso em: 08 sep. 2017.

CAMPOS, Pedro Henrique Pereira. Estranhas Catedrais. Niterói: Editora da UFF, 2014.

DOSSIÊ dos mortos e desaparecidos políticos a partir de 1964. Comissão responsável Maria do Amparo Almeida Araújo... et al. Recife : Companhia Editora de Pernambuco, 1995.

FENELON, Déa Ribeiro. Políticas culturais e patrimônio histórico. O Direito à Memória: patrimônio histórico e cidadania. São Paulo: Departamento de Patrimônio Histórico, 1992. 
FERRAZ, Joana D’Arc Fernandes. Os desafios da preservação da memória da ditadura no Brasil. ABREU, Regina; CHAGAS, Mario. SANTOS, Myrian Sepúlveda dos. (Orgs) Museus, Coleções e Patrimônios: narrativas polifônicas. Rio de Janeiro: Garamond, Minc/IPHAN/DEMU, 2007, pp. 48-57. "Anistia no Brasil: a arte de recordar e de esquecer". In PONTES JR., Geraldo Ramos et al (Orgs.). Cultura, Memória e Poder: diálogos interdisciplinares. Rio de Janeiro: EdUERJ, 2013, pp. 33-44.

FERRAZ, Joana D`Arc Fernandes; DANTAS, Cintia Christiele Braga. O vôo Benjaminiano de Klee: 50 anos do Golpe na perspectiva das memórias, dos esquecimentos e dos silêncios. Revista Maracanan. UERJ n.11, Dezembro 2014, p. $126-137$

FOUCAULT, Michel. A Ordem do Discurso. São Paulo: Edições Loyola, 2001. JEUDY, Henri-Pierre. Memórias do Social. Rio de Janeiro: Forense, 1990.

HALBWACHS, Maurice. A Memória Coletiva. São Paulo: Editora Centauro, 2004. NORA, Pierre. Entre Memória e História: a problemática dos lugares. Projeto História, São Paulo, n.10, dez. 1993, p.7-28.

POLLAK, Michael. Memória, Esquecimento, Silêncio. Estudos Históricos. Rio de Janeiro, vol, 2, n.3., 1989.

SANTOS, Myrian Sepulveda dos. Por uma Sociologia dos Museus. Cadernos do CEOM - Ano 27, n. 41, 2014

TODOROV, Tzvetan. Los Usos e los abusos de la memoria. Barcelona: Paidós Ibérica, 2002.

\section{Autores}

\section{Joana DArc Fernandes Ferraz}

Professora do Curso de Sociologia, da Universidade Federal Fluminense (UFF). Militante e membro da diretoria do Grupo Tortura Nunca Mais-RJ.PósDoutorado em Memória e Patrimônio, pelo Programa de Pós-Graduação em Memória Social (UNIRIO).

\section{Lucas Pacheco Campos.}

Doutorando em Políticas Públicas e Formação Humana pela Universidade do Estado do Rio de Janeiro (UERJ), Mestre e Graduado em Administração pela Universidade Federal Fluminense (UFF). Professor assistente da Graduação em Gestão Pública para o Desenvolvimento Econômico e Social na Universidade Federal do Rio de Janeiro (UFRJ). Membro da Diretoria Colegiada do Grupo Tortura Nunca Mais/RJ. 
